\title{
Cost-utility of enoxaparin compared with unfractionated heparin in unstable coronary artery disease Tricia Nicholson*1, Alistair McGuire ${ }^{2}$ and Ruairidh Milne ${ }^{1}$
}

\author{
Address: ${ }^{1}$ Wessex Institute for Health Research and Development, University of Southampton, Southampton, UK and ${ }^{2}$ Economics \\ Department, City University, London, UK \\ E-mail: Tricia Nicholson* - apn@soton.ac.uk; Alistair McGuire - A.Mcquire@city.ac.uk; Ruairidh Milne - R.Milne@soton.ac.uk \\ *Corresponding author
}

BMC Cardiovascular Disorders 200 I, I:2

\author{
Accepted: 15 October 2001
}

This article is available from: http://www.biomedcentral.com//47/-226I///2

(c) 200I Nicholson et al; licensee BioMed Central Ltd. Verbatim copying and redistribution of this article are permitted in any medium for any noncommercial purpose, provided this notice is preserved along with the article's original URL. For commercial use, contact info@biomedcentral.com

\begin{abstract}
Background: Low molecular weight heparins hold several advantages over unfractionated heparin including convenience of administration. Enoxaparin is one such heparin licensed in the UK for use in unstable coronary artery disease (unstable stable angina and non-Q wave myocardial infarction). In these patients, two large randomised controlled trials and their meta-analysis showed small benefits for enoxaparin over unfractionated heparin at 30-43 days and potentially at one year.

We found no relevant published full economic evaluations, only cost studies, one of which was conducted in the UK. The other studies, from the US, Canada and France, are difficult to interpret since their resource use and costs may not reflect UK practice.

Methods: We aimed to compare the benefits and costs of short-term treatment (two to eight days) with enoxaparin and unfractionated heparin in unstable coronary artery disease. We used published data sources to estimate the incremental cost per quality adjusted life year (QALY), adopting a NHS perspective and using 1998 prices.

Results: The base case was a 0.013 QALY gain and net cost saving of $£ 317$ per person treated with enoxaparin instead of unfractionated heparin. All but one sensitivity analysis showed net savings and QALY gains, the exception (the worst case) being a cost per QALY of $£ 3,305$. Best cases were a $£ 495$ saving and 0.013 QALY gain, or a $£ 317$ saving and 0.014 QALY gain per person.

Conclusions: Enoxaparin appears cost saving compared with unfractionated heparin in patients with unstable coronary artery disease. However, cost implications depend on local revascularisation practice.
\end{abstract}

\section{Background}

Advantages of low molecular weight heparins over unfractionated heparin include convenience of administration, higher bioavailability and the lack of need for monitoring. Some varieties are now used in the treatment of unstable angina and non-Q wave myocardial in- farction (henceforth referred to as unstable coronary artery disease). These conditions are common in hospital and may be increasing. Incidence of unstable angina ranges from 99 to 246 per 100,000[1,2] and approximately $20-38 \%$ of myocardial infarctions are non-Qwave [3]. 
A recent meta-analysis [4] compared low molecular weight heparins (enoxaparin, dalteparin and nadroparin) with unfractionated heparin in unstable coronary artery disease. The short-term treatment comparison combined the results from 5 randomised controlled trials $(12,169$ patients). The overall result suggested that the low molecular varieties were no more effective than unfractionated heparin, odds ratio 0.88 (95\% confidence intervals 0.69-1.12), for the combined outcome of death or myocardial infarction. This was controversial as the meta-analysis used outcomes at the end of equal duration of treatment, but this varied across the trials. In addition, some authors [5] felt that it was inappropriate to combine the different varieties due to their pharmacological differences, despite the lack of statistical heterogeneity detected between the trials.

Our current analysis considered only enoxaparin. This variety is licensed in the UK for unstable coronary artery disease and has the largest body of research evidence. Two large randomised controlled trials $[6,7]$ and their meta-analysis [8] (comprising 7081 patients) showed small relative benefits for enoxaparin over unfractionated heparin at 30-43 days and potentially at one year [9]. This was for the primary composite outcome of death, myocardial infarction, recurrent angina or revascularisation (coronary artery bypass grafting and percutaneous transluminal coronary angioplasty, PTCA). A third small randomised controlled trial [10], reported in an abstract, found mostly worse outcomes for the enoxaparin group.

We found no published full economic evaluations of enoxaparin compared with unfractionated heparin, only cost studies, one of which was conducted in the UK [11]. The other studies, from the US [12], Canada [13,14] and France [4], are difficult to interpret since their resource use and unit costs may not reflect UK practice and simple currency conversions can markedly affect overall costs. However, for information, their results in their base currency and when converted to UK pounds are summarised in Table 1. It should be noted that the studies are not directly comparable as, for example, they include different cost items, different patient groups (in some cases using effectiveness estimates from country sub-groups), and different cost years. The current study builds on our previous work for the former South East/South West Development and Evaluation Committee [15], but includes more extensive analyses and incorporates the most recent published evidence.

This study aimed to compare the benefits and costs of short-term treatment (two to eight days) with enoxaparin or unfractionated heparin in the treatment of unstable coronary artery disease, using published data sources to model cost-utility. We chose to perform a cost- utility rather than cost-effectiveness analysis because there were several outcomes of interest (namely death, myocardial infarction and recurrent angina). Multiple outcomes can be combined through cost-utility analyses. A further advantage over cost-effectiveness is that the outcome of the cost-utility analysis is a cost per quality adjusted life year (QALY) that incorporates both quality and length of life. This also makes it is possible to compare within and across treatment areas (although rankings are potentially misleading where methods and settings differ) $[16,17]$. The analysis adopted a National Health Service (NHS) perspective, since the purpose was to assist NHS decision-makers in the UK.

\section{Methods \\ Effectiveness}

To assess the benefits and harms of enoxaparin, we searched the Cochrane Library, Medline and Embase for randomised controlled trials. Two large double-blind trials $[6,7]$ and a third small randomised trial $[10]$ were found. Full details of the searches, inclusion criteria, appraisal and data extraction methods and tables of results are available in the Additional Material 1: Section A and Additional material 3: Section C

The first trial [6] compared two to eight days treatment using enoxaparin or unfractionated heparin. The primary composite outcome of death, myocardial infarction or recurrent angina at 14 days was more common in the unfractionated heparin group, a difference maintained at one year (relative risk reduction $16.2 \% \mathrm{P}=0.02$ [6] and $10.7 \% \mathrm{P}=0.02$ [9] respectively). Similarly, more revascularisations (coronary artery bypass grafting or PTCA) were required in the unfractionated heparin group at 30 days and one year.

The second trial [7] included two comparisons; enoxaparin or unfractionated heparin to eight days, followed by enoxaparin or placebo to 43 days. At eight days, the triple endpoint (death, recurrent myocardial infarction or urgent revascularisation) was more frequent in the unfractionated heparin group (relative risk reduction $14.6 \% \mathrm{P}=0.048)$.

Both were good quality trials, scoring five and three on the Jadad scale [18]. The following limitations were detected in one study [7]; incomplete description of withdrawals and modification of inclusion criteria during the trial. Their meta-analysis [8] found the enoxaparin group's composite endpoint was significantly reduced to 43 days. However, the only outcome reported separately was death and so these results could not be used in the cost-utility model. 
Table I: Results of economic (cost) studies

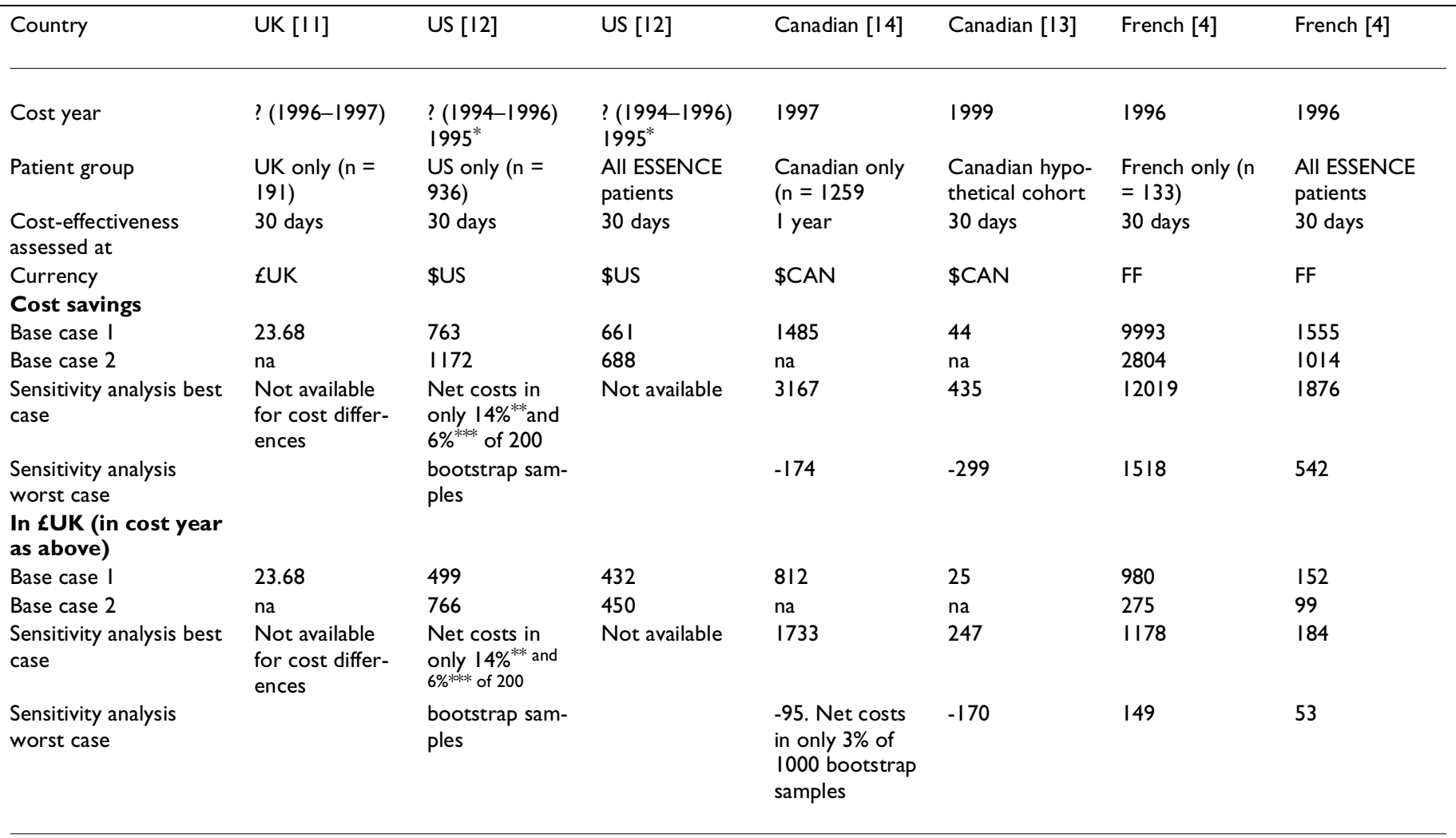

Notes $?$ means unclear na $=$ not applicable Negative cost savings indicates a net cost $*$ taken as 1995 for currency conversion ${ }^{* *}$ initial hospitalisation $* * *$ cumulative total Cost savings converted to UK pounds using Purchasing Power Parities (PPP) [23] (this eliminates the differences in price levels between countries). ESSENCE patients were the patients in the 'Efficacy and Safety of Subcutaneous Enoxaparin in Non-Q wave Coronary Events' trial [6]

The third trial [10] was a small randomised controlled trial, but only reported in an abstract. It found mostly worse outcomes for the enoxaparin group, but differences were not statistically significant and the trial was under powered. The study did not appear to be double blind, and although patients were followed up for 30 days it was unclear when the outcomes had been measured. For these reasons it was not possible to extract data for the model.

In order to quantify the benefits from treatment we used the individual components of the composite outcome although the latter were not statistically significant. The base case used the first trial's most severe event rates to one year [9]. We estimated mean event free times gained for deaths, myocardial infarctions and recurrent angina using survival analysis techniques (actuarial method) to estimate the area between the survival curves. Sensitivity analyses used all events or the second trial's results [7] assuming event rates at 43 days were maintained to one year, as in the first trial (see Table 2).

\section{Quality of life}

Mean health-related quality of life changes associated with death, myocardial infarction and recurrent angina were based on preference weights of patients with suspected myocardial infarction [19] (full details in Additional material 2: Section B). We combined these with the mean event free times to estimate the QALYs gained by treatment.

\section{Resource use and costs}

All costs were in 1998 UK pounds and since data were only modelled for one year, discounting was unnecessary. The valuation of treatment-related costs and savings and average and minimum/maximum values used in the base case and sensitivity analyses are shown in the Additional material 2: Section B. To ensure generalisability within the UK, we used national costs supplemented by local costs (or resource use information) where necessary.

Table 3 shows how the cost difference between enoxaparin and unfractionated heparin was reduced when ad- 
Table 2: Base case and ranges of efficacy, quality of life, resource use and cost data used (amalgamation of all models)

\begin{tabular}{|c|c|c|}
\hline & Base case & Lower, Upper \\
\hline \multicolumn{3}{|l|}{ Effectiveness data } \\
\hline \multicolumn{3}{|c|}{$\begin{array}{l}\text { Mean event free years. Values used in sets, not individually for each out- } \\
\text { come. }\end{array}$} \\
\hline Life years gained & 0.010 & 0.002 , same as base case \\
\hline Myocardial infarction free time gained & 0.007 & $0.008,0.013$ \\
\hline Time free from recurrent angina & 0.018 & $0.014,0.022$ \\
\hline \multicolumn{3}{|l|}{ Quality of life data } \\
\hline \multicolumn{3}{|l|}{ Values used in sets, not individually for each outcome. Quality of } \\
\hline \multicolumn{3}{|c|}{ life change associated with } \\
\hline Death & 0.977 & same as base case, no upper \\
\hline myocardial infarction (Q-wave) & 0.160 & 0.102 , no upper \\
\hline Non-Q-wave myocardial infarction & 0.088 & 0.056 , no upper \\
\hline \multicolumn{3}{|l|}{ Resource use (per person) } \\
\hline Treatment duration (days) & 2.6 & 2,8 \\
\hline Coronary artery bypass grafting rates at one year & 0.014 & $-0.013,0.041$ \\
\hline Angioplasty rates at one year & 0.042 & $0.014,0.070$ \\
\hline Length of stay at 30 days (days) & 0.40 & $-0.50,0$ \\
\hline Myocardial infarction rates at one year (Model 3 only) & 0.006 & same as base case, 0.013 \\
\hline Recurrence of angina at one year (Model 3 only) & 0.017 & same as base case, 0.021 \\
\hline \multicolumn{3}{|l|}{ Drug treatment costs per person 1} \\
\hline Enoxaparin, drug alone per day & $E 12.16$ & $£ 9.00, £ \mid 4.29$ \\
\hline Unfractionated heparin loading dose \& saline flush & $£ 0.52$ & $£ 0.41, £ 0.73$ \\
\hline Consumables for loading dose & $£ 0.14$ & same as base case, $£ 0.16$ \\
\hline Unfractionated heparin drawn-up in saline per day & $£ \mid .83$ & $£ 1.37, £ 2.46$ \\
\hline Pump-related costs per day & $£ 1.79$ & $£ 1.27, £ 2.54$ \\
\hline Monitoring (aPTT tests) per day & $£ 3.67$ & $0, £ 3.8 \mathrm{I}$ \\
\hline $\begin{array}{l}\text { Difference in nursing time between enoxaparin and } \\
\text { unfractionated heparin (cost over } 2.6 \text { days) }\end{array}$ & $£ 3.39$ & $€ 2.95, € 4.36$ \\
\hline \multicolumn{3}{|l|}{$\begin{array}{l}\text { Treatment costs (per person) } \\
\text { (*including length of stay) }\end{array}$} \\
\hline Coronary artery bypass grafting ${ }^{*}$ & $£ 6,534$ & $£ 5,933, £ 6,952$ \\
\hline Angioplasty* & $€ 1,803$ & $£ 1,647, £ 2,823$ \\
\hline Treatment of acute myocardial infarction* (Model 3 only) & $€ I, 150$ & $£ 863, £ 1,385$ \\
\hline Treatment of angina* (Model 3 only) & $£ 549$ & $£ 4 \mid 8, € 758$ \\
\hline Per in-patient day & $£ 399$ & $f 196$, same as base case \\
\hline
\end{tabular}

Notes: I Upper value includes VAT where appropriate.

ministration costs were included. Other differences in resource use associated with enoxaparin treatment are summarised in Table 2.

We assumed that the cost per day for the length of stay included resource use for adverse events such as haemorrhage. Outpatient follow-up, ambulance transport and non-NHS costs were excluded. Where required (model 3 - see below), treatment costs of myocardial infarction and recurrent angina were based on resource use of the most severe event at one year from one trial [9] for the base case and all events for the upper value.

\section{Model and sensitivity analyses}

The sources of the base case and ranges used in the analyses are shown in the Additional Materials:

Section B. We combined these data to estimate the incremental cost per QALY of enoxaparin compared with unfractionated heparin treatment based on the following three scenarios:

1. Base case: Difference in treatment-related costs minus potential savings (from revascularisations (coronary artery bypass grafting and angioplasty) and length of stay). 
2. As for scenario 1, but including Value Added Tax (VAT

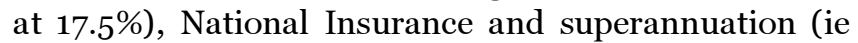
transfer payments) since the NHS must pay these.

3. As for scenario 1, but including treatment costs of cardiac events (myocardial infarctions and recurrent angina) instead of differences in length of stay. The unit costs for length of stay should be interpreted with caution due to somewhat arbitrary accounting. This scenario was used to determine whether the alternative approach (treatment of cardiac events) produced much difference.

One-way sensitivity analyses were performed to determine how robust estimates were to the assumptions.

\section{Results}

The base case was associated with a QALY gain of 0.013 and negative net costs (ie cost savings) of $£ 317$ for each person treated with enoxaparin instead of unfractionated heparin. Table 4 shows the range of incremental net costs and QALYs resulting from the scenarios and oneway sensitivity analyses. There were net cost savings and QALY gains in all but one case. The latter was due to the longer length of stay for the UK cohort [6] that resulted in a net cost of $£ 42$ and hence cost per QALY of $£_{3,305}$. However, there was still a net cost saving $(£ 158)$ if there was no difference in length of stay.

Results were robust to changes in treatment duration and related costs, and the unit cost of coronary artery bypass grafting. Results were moderately sensitive to changes in the unit cost of angioplasty and very sensitive to variation in rates of revascularisation, and the duration and unit cost of length of stay. Similarly, using differences in treatment costs for myocardial infarctions and recurrent angina instead of the mean length of stay (third scenario) had a large impact on net cost savings. Changes in mean event free times reduced the QALY gain by up to three fold.

Table 3: Drug and administration costs for enoxaparin and unfractionated heparin

\begin{tabular}{|c|c|c|c|}
\hline Average costs excluding VAT & $\begin{array}{l}\text { Unfractionated } \\
\text { heparin }\end{array}$ & Enoxaparin & Difference \\
\hline \multicolumn{4}{|l|}{ Daily costs } \\
\hline Drug alone & $£ 0.95$ & 612.16 & $f|1.2|$ \\
\hline $\begin{array}{l}\text { Administration (saline, consumables, intra-venous pump; } \\
\text { monitoring; nursing time) }\end{array}$ & $€ 7.52$ & na & $€ 7.52$ \\
\hline Total cost & $£ 8.47$ & $€ 12.16$ & $£ 3.69$ \\
\hline \multicolumn{4}{|l|}{ Loading dose } \\
\hline Drug alone & $£ 0.29$ & na & $£ 0.29$ \\
\hline Administration & $£ 0.70$ & na & $£ 0.70$ \\
\hline Total cost & $£ 0.99$ & na & $£ 0.99$ \\
\hline Total treatment costs for base case ( 2.6 days) & $£ 23.02$ & $£ 31.62$ & $€ 8.60$ \\
\hline
\end{tabular}

Table 4: Range of net costs and QALYs resulting from scenarios and one-way sensitivity analyses

\begin{tabular}{|c|c|c|}
\hline \multirow[b]{2}{*}{ Item varied } & \multicolumn{2}{|c|}{ QALY or cost per person } \\
\hline & Lower & Upper \\
\hline Base case (per person): & not applicable & not applicable \\
\hline \multicolumn{3}{|c|}{ QALY gain 0.013} \\
\hline \multicolumn{3}{|c|}{ Net cost $-t 317$ (ie cost saving for enoxaparin) } \\
\hline Event free time gained & 0.004 QALYs & 0.014 QALYs \\
\hline Quality of life associated with event & 0.012 QALYs & na \\
\hline Treatment duration & $-€ 298$ & $-€ 320$ \\
\hline \multicolumn{3}{|l|}{ Length of stay } \\
\hline Difference in length of stay & $£ 42$ (ie $£ 3,305 / Q A L Y$ ) & $-£ 158$ \\
\hline Cost per length of stay & $-£ 236$ & na \\
\hline
\end{tabular}


Table 4: Range of net costs and QALYs resulting from scenarios and one-way sensitivity analyses (Continued)

\begin{tabular}{|c|c|c|}
\hline Difference in coronary artery bypass grafting rates & $-£ \mid 40$ & $-£ 495$ \\
\hline Difference in angioplasty rates & $-£ 242$ & $-£ 368$ \\
\hline Cost of coronary artery bypass grafting & $-£ 309$ & $-£ 323$ \\
\hline Cost of angioplasty & $-£ 3 \mid 1$ & $-£ 360$ \\
\hline \multicolumn{3}{|l|}{ Unfractionated heparin costs } \\
\hline Unfractionated heparin loading dose and saline flush & $-£ 3 \mid 4$ & $-€ 318$ \\
\hline Unfractionated heparin drawn-up in saline & $-£ 313$ & $-£ 318$ \\
\hline Pump-related & $-£ 312$ & $-£ 318$ \\
\hline Monitoring (activate partial thromboplastin time tests) & $-£ 308$ & $-£ 318$ \\
\hline Nursing time & $-£ 3 \mid 4$ & $-£ 318$ \\
\hline Enoxaparin costs & $-€ 3 \mid 4$ & $-£ 326$ \\
\hline \multicolumn{3}{|l|}{$\begin{array}{l}\text { Scenario 3: Treatment of cardiac events } \\
\text { (not mean length of stay) }\end{array}$} \\
\hline Myocardial infarction rate and recurrence of angina & $-£ \mid 74$ & $-£ 184$ \\
\hline Cost to treat acute myocardial infarction & $-f|8|$ & $-£ 187$ \\
\hline Cost to treat angina & $-€|8|$ & $-£ 189$ \\
\hline
\end{tabular}

Notes: See Table 2 for ranges used. As there was little difference between scenarios I and 2, we amalgamated the results. Negative net costs indicate cost saving if using enoxaparin. Net costs and QALY gains are not shown where unaffected by parameter changes. na means not avaliable.

\section{Discussion}

Enoxaparin treatment compared with unfractionated heparin was cost saving with increased effectiveness for the base case. Only one sensitivity analysis produced a net cost ( $£ 42$ per person, cost per QALY of $£ 3,305$ ). The maximum cost saving per person was $£ 495$ (with a 0.013 QALY gain).

The other UK study [11] found net cost savings of $£ 23.68$ per person in contrast to the $£ 317$ in the present study. This appears to be due to the use of alternative unit costs for revascularisations and length of stay, further reinforcing the sensitivity of the results to these variables. Perhaps paradoxically, in the first trial [6], the UK enoxaparin sub-group had a longer length of stay than the unfractionated heparin group, although the authors of the US study [12] suggested that enoxaparin may have helped save the sickest patients who therefore required more treatment.

Interpretation from an UK viewpoint of the other economic studies $[4,12-14]$ is difficult due to their resource use and unit costs being potentially unrepresentative of the UK and the variation in cost year (possibly 19941999). All these studies were based on the first trial [6] and used outcomes at 30 days in all but on case [14]. In contrast, we used results from the second large trial [7] to inform the sensitivity analysis. In addition, sub-group analyses of patients by country are also problematic since the trials were powered for a triple composite of death, myocardial infarction and recurrent angina (or urgent revascularisation). They were not powered for cost outcomes or to detect country differences. Further- more, unlike the other cost studies, ours was a full economic evaluation.

As noted before, the studies are not directly comparable. However, the majority of results from the other studies were also cost saving with a maximum of $£ 1,733$ (in the Canadian patient sub-group [14]). In a minority of results there were net costs $[12-14]$ with a maximum reported cost of $£ 170$ per person [13].

Our study results were moderately sensitive to changes in the unit cost of angioplasty and very sensitive to variation in rates of PTCA. This was similar to both the French study [4] and Canadian sub-group study [13]. Our results were also very sensitive to variation in the duration and unit cost of length of stay. This was also found in the French study [4] for both stay in the intensive care unit and non-intensive care for the ESSENCE [6] patients and French sub-group respectively. In our third scenario, similarly to the Canadian sub-group study [13], results were particularly affected by changes in the composite end-point. These similarities are unsurprising given that all the studies used data from one trial.

\section{Limitations of the study}

All models have limitations. These can be separated into general modelling issues and those specific to the current study.

There are three general limitations of modelling, all of which may be relevant here. Firstly, the potential biases from amalgamation of multiple data sources (in this study effectiveness, quality of life and costs). Secondly, 
the simplifications required may lead to models being unrepresentative of reality. Thirdly, potentially inadequate sensitivity analyses where data variances are unknown, that also may be applicable here and is discussed below. Furthermore, external validity (generalisability) may be weak as results used from international randomised controlled trials reflect efficacy rather than effectiveness. Patient populations, staff in-puts, settings and therapies that differ from the UK, compound this. Shifts in other treatment or lifestyle aspects also influence relative effectiveness. For example, stent rates during angioplasty have increased dramatically since the trials, with improved results but additional costs.

The above limitations of modelling are not specific to this study and are unavoidable in most models. Currently, few models are subsequently validated due to lack of time and resources for data collection and testing. However, alternatives - economic evaluations alongside trials - are usually more expensive and are not always the 'gold standard' since resource use may not reflect routine practice and they may be no more informative than modelling. We do not believe that the study results would be changed, although the magnitude of the potential savings may be smaller - an issue that we return to in the Policy implications section.

A main limitation of the current study was that sensitivity analyses for treatment-related costs principally involved variation in unit costs as ranges for resource use were unavailable. Furthermore, the one-way analyses risked missing possible interactions between variables.

The overall effectiveness estimated in the model was from randomised controlled trials rather than the UK sub-group. There was some variation in effectiveness (eg revascularisation rates) between country sub-groups. However, this was not a prior hypothesis (ie post hoc finding) and to assume that such differences were genuine could have been seriously misleading. The extent of certainty around the effectiveness data was unknown as the simple survival analysis to estimate mean event free times did not take into account censoring and confidence intervals could not be calculated. Similarly, the small range of QALY gains (0.004 to 0.014) reflected limited data available rather than a true effect as it was not possible to calculate confidence intervals for the mean changes in quality of life from the source study [19]. Longer-term data were also unavailable and so extrapolation from 100 days to one year was based on assumptions. In addition, the quality of life estimates were not derived in an ideal manner as they used the Rosser classification [20]. Although widely used, this classification is not based on choice (the 'gold standard' for measuring preferences), it is insensitive to subtle changes [21] and valuations are not exactly reproducible [22]. Nonetheless, these data were the best available as the only published valuations found for the patient group in question.

There were also limitations in other resource use, eg the lack of confidence intervals for nursing times, and separate revascularisation rates from the second trial [7]. Furthermore, whilst most analyses used the most severe event rates in order to avoid double counting, this risked under-estimating QALYs and treatment-related costs for cardiac events.

There are also drawbacks to the unit costs. These were predominantly national costs, a heterogeneous group (NHS hospitals and pay scales, and manufacturers, and published sources) occasionally supplemented by local costs. It is difficult to estimate what the impact of this costing approach may be. The analysis shows enoxaparin had a favourable economic impact under a wide range of assumptions, however there were small differences between the alternatives that could be overturned by estimation errors that may appear small in isolation. Furthermore, the overheads element of the unit costs (for administration, cleaning, electricity, etc.) involves somewhat arbitrary accounting principles. Allocation methods vary between hospitals and therefore cost differences may not reflect true deviations. In addition, contracted prices for drugs, especially non-patented unfractionated heparin, and consumables may be considerably lower but are difficult to obtain, despite moves in the NHS for greater openness about costs.

\section{Policy implications}

Given the robustness of the results to changes in assumptions, a move from unfractionated heparin to enoxaparin appears cost saving and more beneficial in this patient group. We calculated full costs (ie including nursing time and a share of equipment costs (pumps)) that reduce the overall cost difference between the two strategies. However, this also involves a judgement on the opportunity cost of such components. Some potential cost or resource use savings such as consumables and test reagents are clearly realisable. However, other savings (eg staff and the hotel portion of hospital stays) depend on the period of change and whether resources freed can be redeployed efficiently or transferred between budget areas. Short-term increases or decreases in workload may not equate to changes in staffing as people adapt, although they may be released for other tasks. Similarly, savings from pumps are not full realisable until purchase of new ones, although there may be an impact on the staff time involved in obtaining a pump if supplies are shared. Whilst this evaluation adopted a NHS perspective to assist decision-makers, this approach could be criticised 
since a broader, societal view is less likely to reinforce artificial budgetary boundaries.

The purpose of this study was to consider the cost-utility of enoxaparin since decision makers are facing the choice of substituting the traditional unfractionated heparin. However, dalteparin is another low molecular weight heparin licensed in the UK, but the licensing arrangements of other varieties is likely to be different on other countries. Furthermore, this paper was prepared for NHS decision makers and should not be generalised to other health care systems without caution. We noted the impact of revascularisation practices, but there may be other differences in health care politics and reimbursement.

\section{Conclusions}

Moving from unfractionated heparin to enoxaparin appears cost saving and more beneficial in patients with unstable coronary artery disease, although cost implications depend on local revascularisation practice. Further research is needed into the extent that potential savings are realisable and the effect of treatment on risk stratified groups as, with use, treatment thresholds may lower thus increasing total spending without necessarily gaining benefit.

\section{Abbreviations}

ESSENCE Efficacy and Safety of Subcutaneous Enoxaparin in Non-Q wave Coronary Events

PTCA percutaneous transluminal coronary angioplasty

QALYs quality adjusted life years

TIMI Thrombolysis in Myocardial Infarction

VAT Value Added Tax (VAT)

\section{Competing interests}

None declared

\section{Additional material}

\section{Additional material I: Section A: Information} about systematic review methods

This gives fuller explanation to allow readers to assess the adequacy of the methods used to obtain data for the cost-utility model.

Click here for file

[http://www.biomedcentral.com/content/supplementary//47I-226I-I2-SI.doc]

\section{Additional material 2: Section B: Additional in-} formation about health economics methods

This additional information complies with the Drummond et al (1996) guidelines for reporting health economic papers http://www.bmj.com/cgi/content/ full/3/3/7052/275. Furthermore, this section allows readers to test the effect of substituting their own variables.

Click here for file

[http://www.biomedcentral.com/content/supplementary/|47|-226I-I2-S2.doc]

\section{Additional material 3: Section C: Data extrac- tion tables for clinical trials \\ These have been added for completeness as they give full details (including comments about their quality) of the trials used for the effectiveness estimates. Click here for file \\ [http://www.biomedcentral.com/content/supplementary/I47I-226I-I- 2-S3.doc]}

\section{Acknowledgements}

Funding: $\mathrm{TN}$ and RM were funded by the South East Region Research and Development (Development and Evaluation Service)

We thank the members of the former South East/South West Development and Evaluation Committee for their constructive comments on a report on which this paper is partly based. We also thank the referees for their constructive comments that have helped improve the paper in important ways.

Contributors:

Guarantor: Tricia Nicholson

TN: Conception, design, data collection (including literature search), analysis and interpretation, drafting article.

AM: Design, data interpretation, revising article, final approval of version to be published.

RM: Conception, design, data interpretation, revising article, final approval of version to be published.

\section{References}

I. Purcell $\mathrm{H}$ : The epidemiology of unstable angina. $\mathrm{Br} / \mathrm{Cardiol}$ 1998, 5:S3-S4

2. Cairns JA, Singer J, Gent M, Holder DA, Rogers D, Sackett DL, et al: One year mortality outcomes of all coronary and intensive care unit patients with acute myocardial infarction, unstable angina or other chest pain in Hamilton, Ontario, a city of 375,000 people. Can J Cardiol I 989, 5:239-246

3. O'Brien TX, Ross J Jr: Non-Q-wave myocardial infarction: incidence, pathophysiology, and clinical course compared with Q-wave infarction. Clin Cardiol I 989, I 2:III-3-III-9

4. Detournay B, Huet X, Fagnani F, Montalescot G: Economic evaluation of enoxaparin sodium versus heparin in unstable angina: A French sub-study of the ESSENCE trial. PharmacoEconomics 2000, 18:83-89

5. Cohen M, Turpie AGG: Management of unstable angina and myocardial infarction. Lancet 2000, 356:1 I94

6. Cohen M, Demers C, Gurfinkel EP, Turpie AG, Fromell GJ, Goodman $S$, et al: A comparison of low-molecular-weight heparin with unfractionated heparin for unstable coronary artery disease. Efficacy and Safety of Subcutaneous Enoxaparin in Non-Q- 
Wave Coronary Events Study Group. N Engl J Med 1997, 337:447-452

7. Antman EM, McCabe CH, Gurfinkel EP, Turpie AGG, Bernink PJLM, Salein D, et al: Enoxaparin prevents death and cardiac ischemic events in unstable angina/ non-Q-wave myocardial infarction. Results of the Thrombolysis in Myocardial Infarction (TIMI) IIB trial. Circulation 1999, 100:1593-160I

8. Antman EM, Cohen M, Radley D, McCabe CH, Rush J, Premmereur J, et al: Assessment of the treatment effect of Enoxaparin for unstable angina/non-Q-wave myocardial infarction. TIMI I IB - ESSENCE meta-analysis. Circulation 1999, I00:1602-1608

9. Fox K: The role of the antithrombins in improving outcome in unstable angina. Br J Cardiol 1998, 5:S7-S9

10. Kuch M, Chmielewski M, Swiatowie A, Mamcarz A, Braksator W, Dhizniewski $M$, et al: Could heparin or enoxaparin added to aspirin alone therapy reduce cardiac events in patients suffering from unstable angina pectoris? - Study performed in 201 patients. Kardiologia Polska 1997, 47:1-140

II. Fox KA, Bosanquet N: Assessing the UK cost implications of the use of low molecular weight heparin in unstable coronary artery disease. $\mathrm{Br} J$ Cardiol 1998, 5:92-105

12. Mark DB, Cowper PA, Berkowitz SD, Davidson-Ray L, DeLong ER, Turpie AG, et al: Economic assessment of low-molecularweight heparin (enoxaparin) versus unfractionated heparin in acute coronary syndrome patients: results from the ESSENCE randomized trial. Circulation 1998, 97:1702-1707

13. Balen RM, Marra CA, Zed PJ, Cohen M, Frighetto L: Cost-effectiveness analysis of enoxaparin versus unfractionated heparin for acute coronary syndromes: A Canadian hospital perspective. PharmacoEconomics 1999, 16:533-542

14. O'Brien BJ, Willan A, Blackhouse G, Goeree R, Cohen M, Goodman $S$ : Will the use of low-molecular-weight heparin (enoxaparin) in patients with acute coronary syndrome save costs in Canada? Am Heart / 2000, I39:423-429

15. Nicholson T, Milne R, Stein K: Dalteparin and enoxaparin for unstable angina and non-Q-wave myocardial infarction: update. Development and Evaluation Committee Report No. 108. 2000. Southampton, Wessex Institute for Health Research and Development. [http://www.hta.nhsweb.nhs.uk/rapidhta/]

16. Drummond M, Torrance G, Mason J: Cost-effectiveness league tables: More harm than good? Sci Med 1993, 37:33-40

17. Gerard K, Mooney G: QALY league tables: handle with care. Health Econ 1993, 2:59-64

18. Jadad AR, Moore RA, Carroll D, Jenkinson C, Reynolds DJ, Gavaghan $\mathrm{DJ}$, et al: Assessing the quality of reports of randomized clinical trials: is blinding necessary? Control Clin Trials 1996, 17:1-12

19. Rawles J, Light J, Watt M: Quality of life in the first $\mathbf{I} \mathbf{0 0}$ days after suspected acute myocardial infarction - a suitable trial endpoint? J Epidemiol Community Health 1992, 46:612-616

20. Rosser R, Kind P: A scale of valuations of states of illness: is there a social consensus? Int J Epidemiol 1978, 7:347-358

21. Brazier J, Deverill M, Green C, Harper R, Booth A: A review of the use of health status measures in economic evaluation. Health Technol Assess 1999, 3 :

22. Gudex C, Kind P, van Dalen H, Durand M-A, Morris J, Williams A: Comparing scaling methods for health state valuations: Rosser revisited. I 07. 1993. York, Centre for Health Economics, University of York

23. Purchasing power parities for GDP. 200 I Web 200 I [http:// www.oecd.org/std/pppoecd.xls]

\section{Publish with BioMed Central and every} scientist can read your work free of charge

"BioMedcentral will be the most significant development for disseminating the results of biomedical research in our lifetime." Paul Nurse, Director-General, Imperial Cancer Research Fund

Publish with BMC and your research papers will be:

- available free of charge to the entire biomedical community

- peer reviewed and published immediately upon acceptance

- cited in PubMed and archived on PubMed Central

- yours - you keep the copyright

Submit your manuscript here:

http://www.biomedcentral.com/manuscript/ 